\title{
Tracheobronchography and balloon dilatation in acquired neonatal tracheal stenosis
}

\author{
P Bétrémieux, C Tréguier, P Pladys, J Bourdinière, G Leclech, C Lefrancois
}

\begin{abstract}
Between 1988 and 1992, 18 mechanically ventilated newborn babies (mean weight $1300 \mathrm{~g}$ and gestational age 30 weeks) presented with deteriorating respiratory failure at a mean age of 29 days. All developed increased oxygen requirements, hypoxic and hypercapnic episodes, and radiological changes of fixed lobar emphysema or recurrent atelectasis which sometimes changed sides from one day to another. Tracheobronchography with iopydol-iopydone was normal in five $(27 \%)$ cases, but in 13 showed tracheobronchial stenosis localised to the lower trachea (seven cases), to the right main bronchus (three cases), or including the left main bronchus (four cases). Eleven of these 13 patients underwent endoscopy and balloon dilatation of the stenotic area. Five patients died, one before endoscopy, one immediately after endoscopies, and three subsequently with severe bronchopulmonary dysplasia. The other six babies recovered without any sequelae after balloon dilatation.
\end{abstract}

(Arch Dis Child 1995; 72: F3-F7)

Keywords: tracheobronchography, balloon dilatation, tracheal stenosis.

Tracheal stenosis in the newborn used to be either subglottic and related to inadequate intratracheal tube diameter, ${ }^{12}$ or congenital and of malformative origin. Nevertheless, in unusually tiny babies some authors have reported distal stenosis of the trachea and main bronchus stenosis. ${ }^{3-6}$ Most series report only small numbers of babies, so epidemiological data about morbidity and mortality are not available. In premature ventilated babies the worsening of respiratory function during the fourth week of life and radiological evidence of asymmetry in the lungs are likely to be caused by acquired tracheobronchial stenosis (ATBS). ${ }^{5}$ In these circumstances most clinicians carry out a bronchoscopy to reach the diagnosis. ${ }^{3-6}$ Nevertheless, this procedure can cause severe problems and caution should be exercised. We describe a novel approach which combines tracheobronchography and endoscopic balloon dilation, thus permitting diagnosis and treatment of this condition.

\section{Methods}

Between 1988 and 1992, 1002 newborn infants received artificial ventilation. Eighteen of them underwent tracheobronchography because they had one or several clinical and radiological findings indicative of ATBS: difficulties with extubation (three cases); clinical sensation of coming up against an obstacle during tracheal suctioning (two cases); bloody suctioned material (one case); or radiological evidence of fixed emphysema, recurrent atelectasis in the same area (10 cases) or conversely; 'alternate' atelectases (two cases) that changed sides from one day to another; bilateral (two cases) or unilateral (one case) pulmonary emphysema with severe mediastinal displacement and association of lobar emphysema with lobar atelectasis (two cases).

The gestational age of the babies was 28 to 36 weeks (median 30) and their birthweights were 935 to $2520 \mathrm{~g}$ (median $1400 \mathrm{~g}$ ).

All had been intubated at birth in the delivery room, then transported under mechanical ventilation to the neonatal unit. The median of the Apgar score at birth was 4 and in three babies it was 0 . The intubation route was nasotracheal. We used VYGON (Ecouen, France) $2.5 \mathrm{~mm}$ diameter tubes; the distal end of the tube was $5 \mathrm{~mm}$ above the carina, confirmed by chest $x$ ray picture. The right main bronchus of one patient had been inadvertently intubated when admitted in the intensive care unit. Eleven had been reintubated once or several times since birth. All were mechanically ventilated with BearCub BP2001 or Babylog Drager using a 'conventional' method (controlled ventilation, inspiration:expiration ratio $=1: 1$ or $1: 2$, peak pressure below $25 \mathrm{~cm} \mathrm{H}_{2} \mathrm{O}$, positive end-expiratory pressure (PEEP) below $6 \mathrm{~cm} \mathrm{H}_{2} \mathrm{O}$, rate below 60/minute), with humidification (BEAR VH820).

Thirteen babies had hyaline membrane disease, six received Exosurf (after 1990). Four presented with one or several pneumothoraces which had been drained. Four developed severe bronchopulmonary dysplasia (BPD) with clinical dependency on mechanical ventilation and oxygen after 28 days (stage IV, as defined by Northway et $a l^{7}$ ). Four babies had severe maternofetal infection due to group B Streptococcus. Ten presented at one time with either pulmonary infection or tracheal colonisation with Staphylococcus aureus or $S$ epidermidis. 


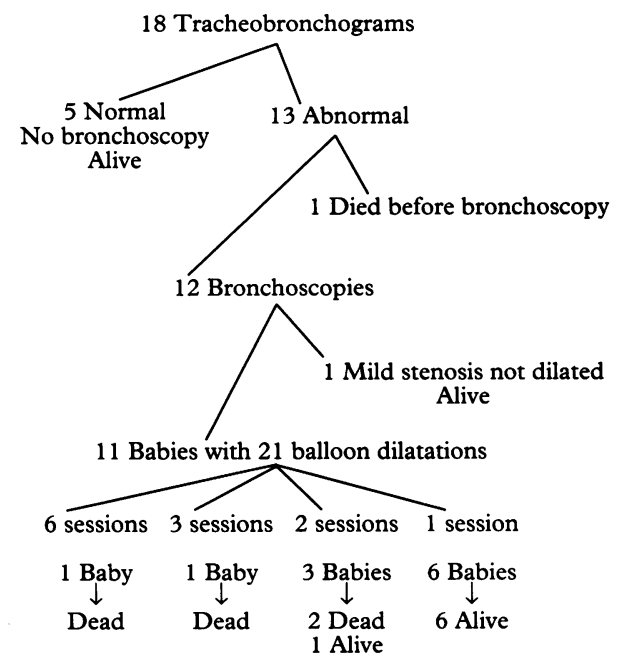

Figure 1 Strategy for diagnosis and treatment.

\section{TRACHEOBRONCHOGRAPHY}

This procedure was performed in the intensive care unit without moving the child from its radiant warmer. A $\mathrm{TcPO}{ }_{2}-\mathrm{TcPCO}_{2}$ probe and a pulse-oximeter permitted non-invasive monitoring of gases during the examination while a cardioscope provided the child's heart rate. A fine suction catheter was filled with $0.25 \mathrm{ml}$ of prewarmed iopydol-iopydone (Hytrast). The child was disconnected from the respirator. The catheter was pushed to the extremity of the tracheal tube which had been located by an external mark and the radiologist injected $0.2 \mathrm{ml}$ of Hytrast, followed by $5 \mathrm{ml}$ air. The catheter was removed and a first plain film $x$ ray picture was taken. Then the child was manually ventilated for 30 seconds and a second chest $x$ ray picture was then taken. Immediately afterwards the Hytrast was sucked out and the child was put back on to controlled ventilation. Because iodine contrast medium had been used, all surviving children underwent thyroid function screening.

\section{ENDOSCOPIC DILATATION}

This was performed on the babies whose tracheobronchogram was abnormal. The fasted infant was transported to theatre, and anaesthetised with Fluothane. When asleep, the child was extubated and a $2.5 \mathrm{~mm}$ in diameter Storz-Hopkins endoscope (Karl Storz GmbH, Tuttlingen, Germany) was inserted. Careful aspiration allowed the

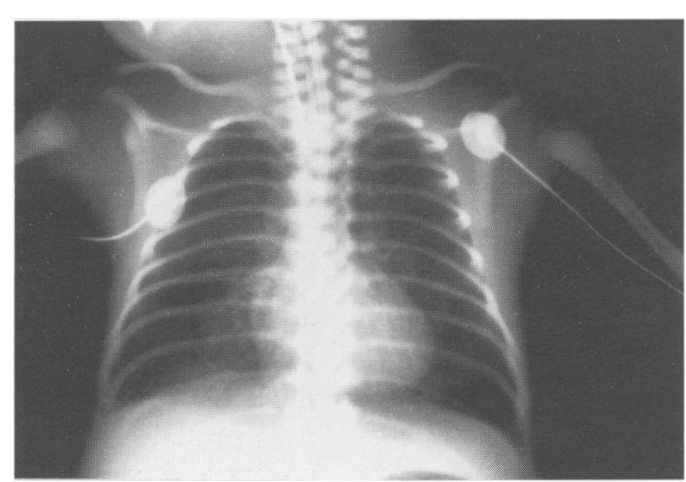

Figure 2 Normal tracheobronchogram in a preterm newborn baby.

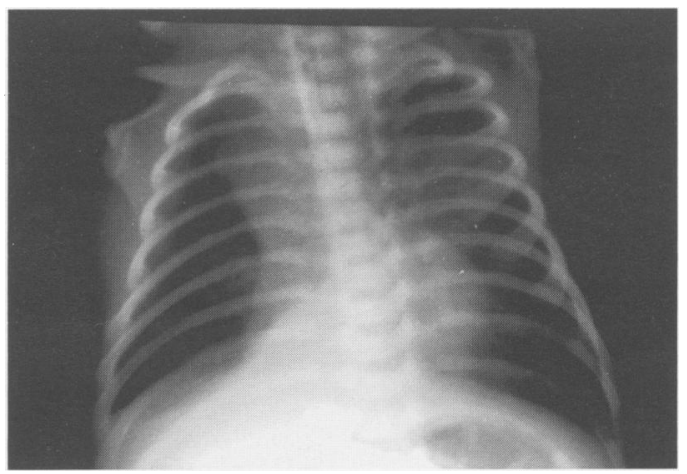

Figure 3 Tracheobronchogram on day 21 in a $1100 \mathrm{~g}$ preterm newborn baby presenting with tracheal stenosis extended into both main bronchi.

trachea to be unblocked from any mucus so that the stenosis could be visualised. During the procedure the child was manually ventilated by the anaesthetist using the bronchoscope, with an oxygen concentration determined by pulse-oximetry.

When stenosis obstructed more than $20 \%$ of the tracheal diameter, balloon dilatation was performed immediately. After checking the balloon, a Fogarty $2 \mathrm{~F}$ arterial embolectomy catheter (Edwards, Santa Anna, California, USA) was introduced through the bronchoscope beyond the stenosis; the balloon was inflated with 0.2 to $0.4 \mathrm{ml}$ air and carefully pulled back through the stenotic area. When the stenosis made it impossible to remove the balloon, it was inflated and left in place for 30 seconds. This was repeated three or four times during the same anaesthetic session, according to the dilatation obtained. The amount of air inflated into the balloon was gradually increased up to $0.8 \mathrm{ml}$. The patient was then reintubated, anaesthesia suspended, and the child was transferred under conventional ventilation.

\section{ADJUVANT TREATMENTS}

When the lesions looked inflamed, systemic glucocorticoid treatment was given after endoscopy. When dilatation seemed to be ineffective, intratracheal adrenaline infusions were attempted. Antibiotics were given after bronchoscopy to all infants whose endotracheal smear contained pathogenic bacteria in pure culture ( $S$ aureus or $S$ epidermidis).

\section{Results}

Tracheobronchography was performed in 18 babies (fig 1). It did not pose any particular problem because the fractional inspired oxygen had to be increased in all patients during the procedure. Neither complication nor bronchospasm was observed. All thyroid function tests were normal.

In five cases, the tracheobronchogram was normal (fig 2) and avoided unnecessary bronchoscopy. These five patients were aged 29 to 36 gestational weeks (median 32) and weighed $1035 \mathrm{~g}$ to $2520 \mathrm{~g}$ (median $1745 \mathrm{~g}$ ). In this group tracheobronchography was performed on the twenty fourth day of life, on 


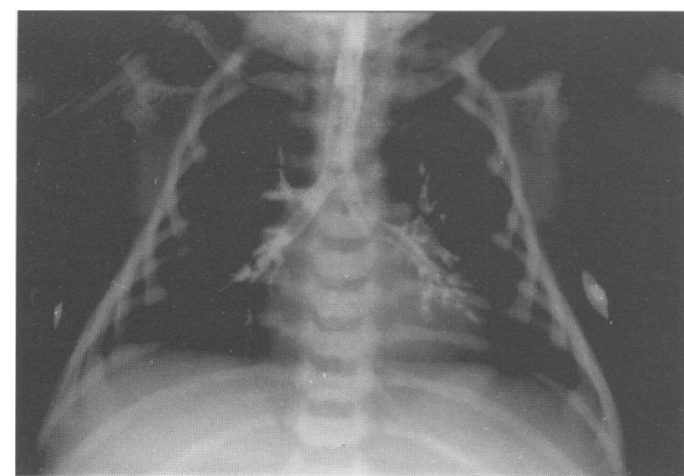

Figure 4 Tracheal stenosis with severe stenosis of the right main bronchus in a $935 \mathrm{~g}$ preterm newborn baby.

average. It was indicated in those babies in whom atelectasis repeatedly occurred in the same lung region.

Thirteen infants had tracheobronchial stenosis (figs 3 and 4). These comprised seven girls and six boys with a gestational age of 30 weeks as a median and a birthweight of $935 \mathrm{~g}$ to $2405 \mathrm{~g}$ (median $1360 \mathrm{~g}$ ). Tracheobronchography was performed on the twenty ninth day, on average. In seven cases the stenosis was in the lower trachea and in three cases it also extended to the right main bronchus. In four cases the right main bronchus only was affected. In two cases the lower trachea was free, but stenosis was observed in the right and left main bronchi. Floppy tracheas collapsing during inspiration (tracheomalacia) were not seen in this series.

Endoscopic dilatation was performed in 11 of the 13 patients. One patient had a minimal stenosis of the right main bronchus and recovered without treatment. He was extubated six days after endoscopy. Another patient developed extremely severe cerebral lesions and died before endoscopy could be performed. Eleven patients received 21 endoscopic dilatations: one had six balloon dilatation sessions; another had three; three patients had two sessions; and six had only one. Treatment was beneficial in seven patients: within a few hours of dilatation, we observed improvements in respiratory function, seen on radiography, atelectases disappeared and the ventilation requirements were reduced. These patients were able to be extubated within six to 39 days after the start of dilatation sessions: none the less all were ventilated for a long time - 66 days on average. Within a five month to five year perspective, these seven infants had no clinical respiratory sequelae and their chest radiographs were normal.

Apart from the patient who died with neurological complications before endoscopy, four other patients died. Their mean body weight was $1188 \mathrm{~g}$, their mean gestational age was $29 \cdot 8$ weeks. In one case, despite three dilatation sessions, stenosis persisted and the infant developed very severe BPD with major hypercapnia. $\mathrm{He}$ died on the forty first day. Another patient presented with the same clinical pattern and died on the seventy fifth day of severe BPD with myocardiopathy. A third patient died on day 150 from $S$ epidermidis and Candida albicans pulmonary infection after six ineffective dilatation sessions. Lastly, a fourth patient died from tension pneumothorax with cardiac arrest within hours of the second dilatation which had been performed with great difficulty on the twenty eighth day. Three of the five dead patients had a post mortem examination: in all three cases this confirmed the integrity of the cartilage rings, ruling out congenital pathology. The stenotic areas were the site of tracheal ulceration, with an inflammatory reaction and giant cell granuloma. Of the five infants who required several dilatation sessions, four died. Of the other patients who underwent post mortem examination during the same period, none had undiagnosed ATBS.

Less serious complications were observed: one infant went into cardiac arrest during the dilatation session and was resuscitated without sequelae; another presented with postdilatation pneumothorax which was drained without any problem. Systemic glucocorticoids were given to five patients.

\section{Discussion}

Tracheobronchography performed in the neonatal intensive care unit can identify the presence of ATBS. Balloon dilatation of the stenotic area seems to be an efficient method of treating ATBS in ventilated premature newborn infants.

The incidence of ATBS seemed to be at least $1.3 \%$ in our series. Only a few authors have related ATBS to the number of mechanically ventilated preterm newborns: the reported incidence ranges from $2 \%{ }^{13}$ to $11 \%$, $^{2}$ but it is likely that milder cases escape diagnosis and resolve spontaneously.

The clinical features of ATBS were quite stereotypical: all babies were born at around 30 weeks and weighed $1400 \mathrm{~g}$; they had a poor Apgar score at birth; all had respiratory distress syndrome, necessitating mechanical ventilation, with repeated reintubations in most cases. Typically, all the clinical and radiological patterns could be attributed to BPD. ${ }^{4}$ Although these two conditions occur together, it is important to be able to differentiate the ATBS pattern because it requires particular diagnosis and treatment.

During the 18 radiological examinations we performed, no adverse incident occurred. The procedure was done in the presence of the intensive care nurse and the fractional inspired oxygen was adjusted to the child's requirements, which generally increased during the procedure. Unlike Elkerbout et $a l^{8}$ we did not observe any case of bronchospasm during or after the examination. The contrast study allowed us to avoid endoscopy in five cases, and we found it to be a simple procedure. The reason for not going directly to bronchoscopy was that it can be extremely dangerous in unstable very tiny babies. Lindahl et al reported seven $(3 \%)$ serious complications among 196 bronchoscopies carried out in 132 neonates; $30(22 \%)$ of them were normal and thus probably unnecessary. ${ }^{9}$ We would like to compare this rate of $22 \%$ with the rate of $27 \%$ for normal tracheobronchograms found in our 
series. In $22-27 \%$ of the cases in which bronchoscopy is indicated from the clinical data, the relatively trivial procedure of bronchography could probably reduce the need for more dangerous bronchoscopy. Considering the currently available means and the ultimate need of rigid tube bronchoscopy in the babies with ATBS, tracheobronchography seems to be a reliable, reproducible, harmless and easy technique which should be carried out before resorting to rigid tube bronchoscopy. In the 12 patients who underwent both tracheobronchography and endoscopy the data from the two examination methods were identical. In the five cases in which bronchography was normal in our series the babies recovered without specific treatment, except for physiotherapy, so we can assume that the asymmetrical radiological findings on the plain chest $x$ ray picture were probably due to transient mucous plugs obstructing the airways. While granuloma and stenosis are clearly seen on tracheobronchography, mucous plugs do not seem to affect the radiological picture.

Some teams have started reporting the use of ultrathin fibreoptic bronchoscopy, using a 2 or $2.5 \mathrm{~mm}$ diameter fibroscope. ${ }^{10} 11$ We have no experience of this technique and it has only been reported once for 'rapid inspection of the airways' before rigid bronchoscopy and balloon dilation. ${ }^{12}$ Nevertheless, it may show the presence of stenosis and changes in calibre during the breathing cycle, but no data would be provided about the length of the stenosis nor could any treatment be carried out during the procedure.

The balloon dilatation technique used in neonates has been described in several series. ${ }^{6812-17}$ As far as is known, this is the largest series ever published, combining tracheobronchography and balloon dilatation. Compared with the surgical techniques attempted by various authors, balloon dilatation has the advantage of being applicable to very tiny babies. Cryotherapy or $\mathrm{CO}_{2}$ laser cannot yet be performed on premature neonates because of anatomical constraints. ${ }^{13}$ Lenoir et al suggested using an angioplasty Cournand $4 \mathrm{~F}$ catheter in a $1100 \mathrm{~g}$ neonate, without inflating the balloon, as they thought that there was a high risk of bronchial or tracheal perforation. In our series we recorded one pneumothorax during bronchoscopy with a good outcome and another one shortly after the procedure, with a fatal outcome. ${ }^{18}$ Thus $18 \%$ of the neonates had an endoscopy related pneumothorax and $27 \%$ sustained some complication. This supports the role of tracheobronchography in avoiding unnecessary bronchoscopy. Nevertheless, no other therapeutic measures are currently available with which to compare it.

In our series of 13 patients with ATBS five died, four after the dilatation procedure. The mortality was thus $33 \%$. Devlieger et al ${ }^{14}$ reported one death in one patient, Elkerbout et $a l^{8}$ reported one death in four $(25 \%)$ patients, and Greenholz et al ${ }^{16}$ reported two deaths in five patients; Friedberg et al ${ }^{17}$ reported one out of three (33\%) and Dab et al $^{12}$ none out of three. In such small series it is rather difficult to draw valid conclusions. Nevertheless, mortality seems to be between $25 \%$ and $40 \%$. Of the five babies necessitating more than one dilatation session, only one survived. This should compel us to search out other treatments, unfortunately, no surgical correction is currently available in such tiny babies. ${ }^{16}$ The necessity of repeating the dilatation sessions could be of prognostic value, but this was not found by $\mathrm{Dab}$ et al ${ }^{12}$ whose three patients had three to 10 bronchoscopies. In our series, the surviving babies had no further respiratory problems. It is worth noting that in a case where stenosis was moderate, as seen during bronchoscopy, the child recovered without any dilatation procedure. Thus we think that minimal lesions may spontaneously resolve with a favourable outcome. In our series no corticoid treatment was given before the occurrence of ATBS. Nevertheless, as babies are now given corticoids earlier to avoid severe BPD, some mild cases of ATBS might benefit from such treatment. In established ATBS, as we report here, neither corticoids nor adrenaline instillations seemed to be effective against the course of the obstructions, but these treatments were given to patients with the most severe illness only and on a random basis.

The pathophysiology of ATBS is unknown, no prospective or case controlled studies being available. Similar cases have been reported but described as congenital tracheal stenosis. ${ }^{5}$ To us and other authors 813141920 numerous factors argue in favour of the acquired, noncongenital, and iatrogenic character of such lesions: the date of occurrence of clinical signs around the fourth week of life; and the absence of subglottic lesions in our series (which is the preferential site of congenital lesions). In the same way, the absence of cartilage ring abnormalities on post mortem examinations as well as the highly inflammatory granuloma discovered point to an acquired pathology. One of our babies was transported from the delivery suite to the neonatal ward with a tracheal tube inserted in the right main bronchus; this seems to argue in favour of the iatrogenic origin of the lesions as already reported by Hennequin et al. ${ }^{21}$ In all babies stenosis was localised either in the lower trachea or in the right bronchus. These areas are preferentially reached during tracheal suctioning. ${ }^{17}$ Bayley et al evidenced the deleterious effects of deep endotracheal suctioning in experimental rabbits. ${ }^{22}$ The slight movements of the tracheal tube during head flexion or extension may induce ulceration at the tip of the tube. ${ }^{23}$ The inflammatory and scarring phenomena that follow this ulceration could lead to stenosis. ${ }^{24}$ The manipulations necessary to achieve good endotracheal positioning in nasotracheally intubated babies may also lead to tracheal epithelial lesions. ${ }^{25}$ The tracheal colonisation which affected 10 of our patients could also favour local stenoses, as demonstrated by Squire et al in animals. ${ }^{26}$ Insufficient humidifying of the inhaled gases has also been implied. ${ }^{4}$ 
Lastly, the deleterious effect of repeated reintubations should not be underestimated.

Acquired tracheobronchial stenosis of ventilated premature babies is a serious disease because of the prolonged need for intensive care which it necessitates and its high mortality. The clinical signs are relatively typical and should be kept in mind when confronted with clinical or radiological ventilation disorders on the fourth week of life in premature neonates weighing less than $1500 \mathrm{~g}$ and around 30 weeks' gestational age at birth. Tracheobronchography performed in the neonatal intensive care unit is a simple, reliable, and safe method to demonstrate these lesions. It provides the endoscopist with useful information and reduces unjustified endoscopies by $27 \%$. Rigid tube tracheobronchoscopy will confirm the diagnosis and permit balloon dilation of the stenosis in the same session. Most of our patients survived without sequelae.

We are grateful to Dr Y Quintin for his help in carrying out this study and to $\mathrm{Dr} M$ Silverman for helpful comments on the manuscript.

1 Dankle SK, Sculler DE, McClead RE. Risk factors for neonatal acquired subglottic stenosis. Ann Otol Rhinol Laryngol 1986; 95: 626-30.

2 Sherman JM,'Nelson H. Decreased incidence of subglottic stenosis using an 'appropriate-size' endotracheal tube in neonates. Pediatr Pulmonol 1989; 6: 183-5.

3 Nagaraj HS, Shott R, Fellows R, Yacoub U. Recurrent lobar atelectasis due to acquired bronchial stenosis in neonates. $\mathcal{F}$ Pediatr Surg 1980; 15: 411-5.

4 Miller RW, Woo P, Kellman RK, Staglet S. Tracheobronchial abnormalities in infants with bronchopulmonary dysplasia. $f$ Pediatr 1987; 111: 779-82.

5 Hauft SM, Perlman JM, Siegel MJ, Muntz HR. Tracheal stenosis in the sick premature infant. Am F Dis Child 1988; 142: 206-9.

6 Grylack L, Anderson K. Diagnosis and treatment of traumatic granuloma in tracheobronchial tree of newborn with history of chronic intubation. F Pediatr Surg 1984; 19: 200-1.

7 Northway WH Jr. Pulmonary disease following respiratory therapy of hyaline membrane disease: bronchopulmonary dysplasia. N Engl f Med 1967; 276: 357-68.
8 Elkerbout SC, van Lingen RA, Gerritsen J, Roorda RJ. Endoscopic balloon dilatation of acquired airway stenosis in newborn infants: a promising treatment. Arch Dis Child 1993; 68: 37-40.

9 Lindhal H, Rintala R, Malinen L, Leijala M, Sairanen H. Bronchoscopy during the first month of life. F Pediatr Surg 1992; 27: 548-50.

10 de Blic J, Scheinmann P. Fibreoptic bronchoscopy in infants. Arch Dis Child 1993; 68: 159-61.

11 Shinwell ES. Ultrathin fiberoptic bronchoscopy for airway toilet in neonatal pulmonary atelectasis. Pediatr Pulmonol 1992; 13: 48-9.

12 Dab I, Malfroot A, Goosens A. Therapeutic bronchoscopy in ventilated neonates. Arch Dis Child 1993; 69; 533-7.

13 Groff DB, Allen K. Gruentzig balloon catheter dilation for acquired bronchial stenosis in an infant. Ann Thorac Surg 1985; 39: 379-81.

14 De Vlieger H, Wilms G, Marchal G, Jaeken J, Baert A, Eggermont E. Sténoses trachéobronchiques du Eggermont E. Sténoses tracheobronchiques du nouveau-né premature. Traitement par
ballonnet. Arch Fr Pediatr 1988; 45: 561-3.

15 Philippart AI, Long JA, Greenholz K. Balloon dilatation of postoperative tracheal stenosis. $\mathcal{F}$ Pediatr Surg 1988; 23 1178-9.

16 Greenholz SK, Hall RJ, Lilly JR, Shikes RH. Surgical implications of bronchopulmonary dysplasia. $f$ Pediatr Surg 1987; 22: 1132-6.

17 Friedberg J, Forte V. Acquired bronchial injury in neonates. Int $\mathcal{F}$ Pediatr Otorhinolaryngol 1987; 14: 223-8.

18 Lenoir P, Bougatef A, Ramet J, Dab I, Cham B, Savre L. Non surgical intervention in the resolution of acquired neonatal bronchial stenosis. Am $\mathcal{f}$ Perinatol 1990; 7: 290-2.

19 Brown SB, Hedlund GL, Glasier CM, Williams $\mathrm{KD}$, Greenwood LH, Gililand JD. Tracheobronchial stenosis in infants: successful balloon dilatation therapy. Radiology 1987; 164: 475-8.

20 Cohen MD, Webert TR, Rao CC. Balloon dilatation of tracheal and bronchial stenosis. Am $\mathcal{F}$ Radiol 1984; 142 477-8.

21 Hennequin Y, Pardou A, Detemmerman D, Vermeylen D, Muller F, Vandermoten G, et al. Partial bronchial stenosis following inadvertent right bronchial intubation in a neonate. Acta Anaesthesiol Belg 1985; 3: 131-6.

22 Bailey C, Kattwinkel J, Kuldeep T, Buckley T. Shallow versus deep endotracheal suctioning in young rabbits: pathosus deep endotracheal suctioning in young rabbits: patho82: $746-51$.

23 Todd DA, John E, Osborn RA. Epithelial damage beyond the tip of the endotracheal tube. Early Hum Dev 1990; 24: 187-200.

24 Lee RM, O'Brodovich H. Airway epithelial damage in premature infants with respiratory failure. Am Rev Respir Dis 1988; 137: 450-7.

25 Roopchand R, Roopnarinesingh S, Ramsewak S. Instability of the tracheal tube in the neonates. A post-mortem study. Anaesthesia 1989; 44: 107-9.

26 Squire R, Brodsky L, Rossman J. The role of infection in the pathogenesis of acquired tracheal stenosis. Laryngoscope 1990; 100: 765-70. 